\title{
Evaluation of the Framework of Urban Tourism in Iraq
}

\author{
Saad Khudhair Al-jumaily*, Eman Tahseen Maki \\ Department of Architecture, College of Engineering, Al-Nahrain University, Baghdad, Iraq \\ Email address: \\ Aljumaily.saad@ymail.com (S. K. Al-jumaily), max1558@yahoo.com (E. T. Maki) \\ ${ }^{*}$ Corresponding author
}

\section{To cite this article:}

Saad Khudhair Al-jumaily, Eman Tahseen Maki. Evaluation of the Framework of Urban Tourism in Iraq. American Journal of Environmental and Resource Economics. Vol. 5, No. 3, 2020, pp. 50-58. doi: 10.11648/j.ajere.20200503.12

Received: July 4, 2020; Accepted: July 16, 2020; Published: July 28, 2020

\begin{abstract}
Most countries seek to develop and protect their economy from collapse and avoid risks, Some countries depend on economic diversification, some depend on natural resources, Like oil to achieve economic growth, including Iraq, which lacks industry, agriculture, and human resources management to support development at the present time for various reasons, the most important of which is relying on selling oil in the first place, And the spending of resources achieved on the local community, therefore, development depends on oil resources only and on the justice of the central government and its vision for development. Iraq is a country rich in its civilization and historical depth in the region. It includes many historical, cultural, natural and religious sites scattered throughout Iraq, but it lacks how to invest in supporting economic development. Accordingly, the research assumes that the resources obtained from urban tourism differ in their effectiveness and their impact on spatial development events from the revenues accruing from the sale of oil. The current research aims to reach mechanisms for converting Iraqi cities into tourist destinations that combine religious, cultural, natural and medical tourism as an entry point to increase opportunities for distributing resources directly to the local community through the idea of urban tourism without relying on oil resources. The results of the practical study of Iraqi cities showed that they are weak cities that do not meet the requirements of urban tourism, although they include a large number of historical sites and civilizational, natural and religious monuments, therefore they need to review policies related to tourism and planning.
\end{abstract}

Keywords: Urban Tourism, Global Competition, Internal Challenges, External Challenges

\section{Introduction}

Cities differentiate among themselves in light of the rapid development of the means of communication and the search for additional resources to achieve development, and these cities must determine their location from this competition after urban tourism has become one of the aspects of this competition and domination and acquisition of the destination of tourists in the world, which is an industry and permanent oil, and the tourist according to The opinion of the United Nations stimulates (60) professions to meet its needs and from this it becomes clear how important places development is in revitalizing the national economy. The United Nations indicates that developing countries describe it as rich in their cultural heritage, but it is a burden on it due to its inability to manage and maintain it. It linked the development of places with the urban tourism industry exclusively within the global competition. Iraq is one of the oil countries that lack the vision, ability and will to achieve development and maintain its sustainability despite its possession of oil resources and cultural and religious sites in addition to its inability to meet the basic needs and aesthetic aspects of cities to occupy its position in a global competition that has become world-class.

Accordingly, there must be a clear vision to form the strategies for moving Iraqi cities to cities attractive to tourism. This vision must meet the basic requirements of any city before moving to the level of competition and tourism as a basic pillar in it: It is to be world-class cities with distinct and varied urban bodies in their sectors, buildings, streets and private and public urban spaces, with clear, strong and interconnected movement and visual axes, whose urban scene will be serial through achieving space containment. It will also be distinguished in the level of organizing sidewalks, furnishing, advertisements, signs, trees, plants, and public service facilities. It is also rich in values, symbols and signs that express the experience, memory, identity of the community, its heritage and its cultural and civilizational 
diversity. With strong appeal and vital centers, it includes a wide variety of possible opportunities for work, life, peaceful coexistence, and the exchange of ideas and experiences among members of society. In order to continuously mean by providing the best amenities, recreation, safety, job opportunities, learning, and services, easy access to it and move between its centers, sectors, and streets.

Therefore, cities must respond to local and global challenges:

1. Responding to the local challenges faced by cities and their suburbs, including (deteriorating urban condition, urban scene, visual and mobility chaos, slums, abuses and land use changes resulting from the ineffectiveness of the applicable legislation, mismanagement of cities and administrative corruption).

2. Responding to global challenges, meaning that Iraqi cities have the ability to compete and face economic, social, cultural, environmental, health, security, psychological, and aesthetic challenges.

Therefore, the importance of urban tourism is playing an essential role to achieve spatial development and the stability and prosperity of local communities are highlighted.

\section{The Framework of Urban Tourism}

According to the United Nations (1999), defined the International Tourism: Persons visiting the country for less than one year, specifically for purposes of recreation or holiday, medical care, religious observances, family affairs, participation in international sport and cultural events, conferences and other meetings, study tours, and other student programs, as well as persons in transit to another country. [1] According to (Colantonio and Potter 2006), the tourism that is held in an urban area of the city is known as urban tourism. [2] urban tourism is defined as "a type of tourism activity which takes place in an urban space with its inherent attributes characterized by non-agricultural based economy such as administration, manufacturing, trade, and services and by being nodal points of transport. [3] Urban tourists can bring substantial economic benefits to cities; [4] Urban tourism encompasses the activities of international and domestic visitors as well as local residents in urban areas, contextualized by built and natural landscapes, amenities, and infrastructure. [5] Urban tourism is a broad concept including all kinds of recreational activities that take place in cities. Urban tourism consists of trips and visits with a focus on town and city destinations, also known as city tourism. [6] The United Nations World Tourism Organization (UNWTO, 2013) defines tourism as "an economic and social phenomenon driving people (tourists) who travel to and stay in places outside their usual environment for not more than one consecutive year for leisure, business and other purposes not related to the exercise of an activity remunerated from within the place visited". [7] Tourism has become one of the major players in international commerce and represents at the same time one of the main income sources for many developing countries. [8] The urban area is one kind of destination for tourists. The destination is a total tourism product that is a combination of resources and services. The urban environment offers social, cultural, physical, and aesthetic aspects where tourist activity can exist. [9] Cities become more develop and attractive today. It is not just a city to improve facilities for the people but also for the tourists. The city is part of the culture and history. It is the epicenter for many of traditions. A city is a place for a unique economic and social opportunity. It brings dynamism and vitality, growth and development, and becomes an essential element in people $s$ lives. [10] The city becomes a place of consumption which takes advantage of entertainment opportunities and tourism, where the urban environment itself becomes a commodity for sale to both investors and individual consumers (Meethan, 1996) [11] Dynamic development of urban tourism is a source of employment and growing incomes in the urban areas as well as a cause of cultural and social growth (increased quality of life, income redistribution). (Urban Tourism), Tourism brings more than just financial benefits to the cities it blesses. It revitalizes and invigorates communities. It connects people; from strangers to friends to family. It is a platform for learning. It is a vehicle for adventure. It teaches people how to live with diversity, how to form connections with people whose culture is vastly different from your own. Tourism is more than just an economic driver; it is a way of life. One that can provide inherent benefits for all that is involved. [12] The tourism industry is multifaceted and consists of a large variety of tour operators, hotel operators, cruise ships, and recreational activity providers. For tourism to be carried out in a sustainable manner, representatives of all of these industries need to be contacted and included in the planning process. [13] the development of urban tourism will affect not only industrial structure and economy development of the city itself, but also the region that the urban tourism development [14] The impacts of tourism can be sorted into seven general categories:

Economic; Environmental; Social and cultural; Crowding and congestion; Services; Taxes; Community attitude. [15] Positive an aspect of tourism is its ability to bring new money into the community, Economic benefits and costs of tourism reach virtually everyone in the region in one way or another. [16] Tourism provides incentives for conserving the natural environment, improves the quality of public spaces, encourages higher standards of local planning, provides incentives for cultural preservation, and increases the range of shops and services. [17] The European Union Framework for action for sustainable urban development aims are: Strengthening economic of cities, Promoting equality of urban areas, Protecting and improving the urban environment, Contributing to good urban governance and local empowerment [18] The cities change in public culture, architecture and design, education, urban planning, parks and leisure, and the public party which resulted from the dramatic redevelopment of the city's central business and historic district. [19] The impacts of tourism can be sorted into seven general categories: 
1. Economic 2. Environmental 3. Social and cultural 4. Crowding and congestion 5. Services 6 . Taxes 7. Community attitude. Specific plans and actions can increase tourism's benefits or decrease the gravity of a negative impact. [20] It is now generally accepted that international tourism constitutes one of the most significant of global trade flows. It is probably the biggest sector in the world economy. [21] It appears through a review of previous literature related to tourism that there are two approaches to tourism, which are requirements of placemaking and urban tourism. which are traditional tourism that depends on its traditional classifications, which are natural tourism, cultural tourism, religious tourism.... etc.? In return, there is contemporary global tourism or what is called global tourism, city tourism, Or competitive urban tourism. The first is a limited tourism industry and the second is a widespread tourism an industry that relies on planning, reuse, and employment of local resources to be world-class. It is an industry that relies on spatial development and the creation of additional non-industrial, agricultural or commercial resources, natural resources such as the extraction and sale of oil, gas, and other resources that are usually dependent On the strong grip on the economy that is managed by the central systems without the participation of the local community, where the oil revenues, for example, come at once and directly to the state and then begin distribution to state institutions to serve the community, on the contrary, tourism revenues Urban comes directly to the local community and faster than oil. Therefore, the contribution of urban tourism to development is direct and starts from the base up to the pyramid, meaning that the state gets its benefits later in the form of fees and taxes. Chart (1) illustrates this relationship.

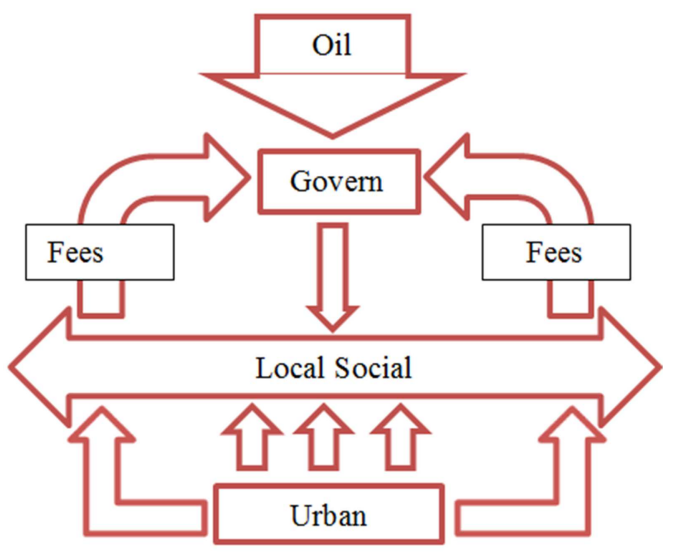

Figure 1. The relationships between Oil Sales and urban Tourism.

It is not surprising that urban tourism is linked to the contemporary global trends of the placemaking, that is, it is related to the quality of urban places or environments, and these trends aim to be sustainable and integrated places with high densities with a variety of land uses free of harmful occupations and also aim to have these places interconnected to encourage People to walk to support the community's health, in addition to isolating the movement of people from the movement of cars by converting streets and public spaces to places for practicing different activities and events. These trends are also concerned with preserving historical sites and traditional environments and reusing old buildings to support the placemaking and thus supporting urban tourism, so if the place making or the tourism industry aims at the urban tourism industry, this will cause a change in uses and increase its quality to improve its efficiency and make it attractive and not repelling local and global tourism These ideas will be addressed in the practical study of Iraqi cities, and to verify their efficiency, quality, and meeting the requirements of places making and urban tourism.

\section{Case Study}

Iraq is one of the countries that include many historical sites, most of which are currently outside the main cities or their surroundings and these sites suffer from a lack of interest in them, maintenance, preservation and linking with the nearby cities, which lost their visitors and those interested in them as a result of its distance and the lack of an efficient transportation network that leads to it. Iraq includes many traditional (old) areas that are still inhabited by the poor people, as they lack attention, maintenance, restoration, preservation, and re-works. On the contrary, these areas were exposed to removing important parts of its traditional fabric, which lost its beauty and traditional characteristics despite its embrace. Religious sites that represent the essence of religious tourism, which made them ineffective for tourism purposes, especially urban tourism, as they lack elements attractive to tourists. There are natural sites for tourism in northern and southern Iraq, but they do not rise to the level of global tourism, due to the lack of services and infrastructure in addition to the presence of a road network unable to meet the requirements of urban tourism. Therefore, in this study, verification will be made of meeting the requirements of urban tourism for Iraqi cities, as they include historical, traditional, natural, and religious sites, in addition to verifying the efficiency of external and internal roads and services that represent the general framework for urban tourism.

\section{Methodology}

In this study, 20 architects were surveyed from Al-Nahrain University graduate students whose residency is distributed in different Iraqi cities, as a study sample to answer the questions that were prepared to represent the general framework of urban tourism.

The main axes of the general framework for urban tourism for Iraqi cities are listed as the following manners:

1. City Centres.

2. Transportation \&Roads.

3. Historical Places and City Centres.

4. Religious Places and the Surrounding area.

These questions included the four above axes according to the tables shown below and were evaluated by the elected sample as in Appendix No. (1). 


\subsection{Evaluation the Organization Levels of City Centers}

1. Level of organization of the urban landscape, the height of buildings, land use, population, and housing densities.

2. Level of the efficiency of cities, economically, socially, urban, environmentally, security, and health.

3. Level of city Compact, interstitial spaces, and their cohesion and interdependence.

4. Level of use of local capital for investment and city management.

5. Level of aesthetics of the exterior, spaces, street furnishing, movement regulation, advertisements, guide signs, and bus parking stops.

6. Level of diversity and distribution of activities and events in the city.

7. Level of harmful professions in the city (service, health, etc.).

8. Level of environmental treatments for buildings, sidewalks, streets, stores, and city centers that encourage people to move and move.

9. Level of attendance of folkloric activities and events in urban spaces (symbols - legends - myths - events - stories local folklore).

10. Level of supply and circulation of housing units and the mixed-use of commercial buildings that surround the main streets of cities.

11. Level of visual pollution in cities.

12. Level of diversity of hotels and their geographical distribution to meet the needs of tourists in cities.

13. The spread of the phenomenon of turning the centers of cities and important streets into health uses.

14. Level of development of river banks and the surrounding spaces.

Table 1. Shows results of evaluation Organization Levels of City Centers.

\begin{tabular}{|c|c|c|c|c|c|}
\hline & Weak & Acceptable & Medium & Good & Very Good \\
\hline & \multicolumn{5}{|c|}{ Evaluation } \\
\hline & 8 & 7 & 3 & 1 & 1 \\
\hline & 9 & 3 & 3 & 2 & 1 \\
\hline & 7 & 4 & 5 & 3 & 1 \\
\hline & 11 & 6 & 1 & 1 & 1 \\
\hline & 13 & 3 & 2 & 1 & 1 \\
\hline \multirow{9}{*}{$\begin{array}{l}\text { Organization } \\
\text { Levels of City } \\
\text { Centers }\end{array}$} & 9 & 7 & 2 & 1 & 1 \\
\hline & 5 & 2 & 3 & 7 & 3 \\
\hline & 13 & 3 & 2 & 1 & 1 \\
\hline & 15 & 2 & 1 & 1 & 1 \\
\hline & 6 & 9 & 2 & 2 & 1 \\
\hline & 4 & 1 & 1 & 4 & 10 \\
\hline & 7 & 7 & 4 & 1 & 1 \\
\hline & 5 & 2 & 2 & 3 & 8 \\
\hline & 15 & 1 & 1 & 2 & 1 \\
\hline
\end{tabular}

Table 1 Shows results of evaluation Organization Levels of City Centers.

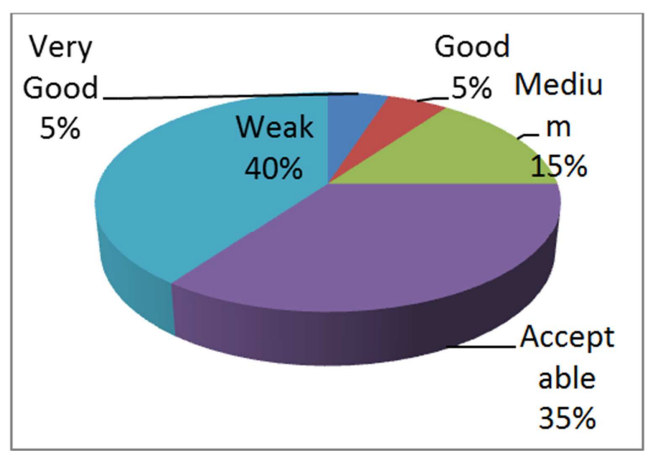

Figure 2. Organization Levels of City Centers.

\subsection{Evaluation the Organization Levels of Public Transportation and External Roads}

1. Level of organization of the external environment surrounding the external roads.

2. Level of the efficiency of the roads that encourage tourists to move and Transits between cities.

3. Level of maintenance, cleaning, lighting, fencing, furnishing, and landscaping of external roads.

4. Level of organization of spaces for religious events, services, and the external environment.

5. Level of organization of public services for visitors to religious places between cities.

6. The presence of public transport (buses - metro railways) for recreational and intercity trips.

7. The presence of convenient private transportation for tourists between cities.

Table 2. Shows results of evaluation levels of organization of public transportation and external roads.

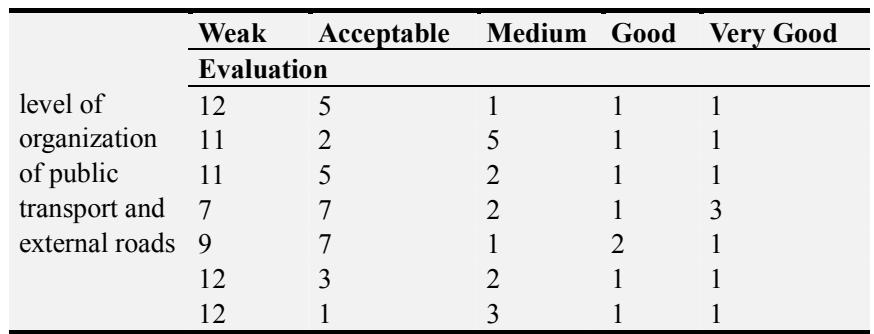

Table 2 Shows results of evaluation levels of organization public transportation and external roads.



Figure 3. Levels of organization of public transportation and external roads. 


\subsection{Evaluation the Historical Sites and City Centres}

1. Level of historical sites meeting the requirements of urban tourism and global competition.

2. Level of linkage of historical sites with city centers.

3. Level of availability of attractions surrounding the historical sites.

4. Level of abuses, slums, and expelling activities that surround the historical sites.

5. Level and clarity of the entrances to historical sites, their accessibility, and their connection to the public road network.

6. Level of security aspects of the surrounding historical and archaeological sites.

7. Level of rehabilitation and maintenance of historical sites.

8. Level of indicative and identifying marks of historical and archeological sites.

9. Level of support of the areas surrounding the historical and archeological sites for urban tourism.

Table 3. Shows results of evaluation levels of Historical sites and city centres.

\begin{tabular}{llllll}
\hline & Weak & Acceptable & Medium & Good & Very Good \\
\cline { 2 - 6 } & Evaluation & 3 & 1 & 1 & 2 \\
\cline { 2 - 6 } Historic & 13 & 4 & 1 & 1 & 1 \\
sites and & 15 & 1 & 2 & 1 & 1 \\
city & 5 & 4 & 1 & 2 & 8 \\
centres & 11 & 5 & 2 & 1 & 1 \\
& 7 & 6 & 2 & 4 & 1 \\
& 11 & 4 & 3 & 1 & 1 \\
& 13 & 4 & 1 & 1 & 1 \\
& 15 & 1 & 2 & 1 & 1 \\
\hline
\end{tabular}

Table 3 Shows results of evaluation levels of Historical sites and city centres.

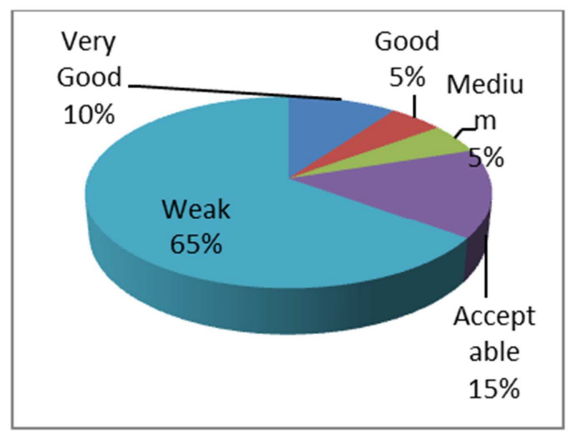

Figure 4. Shows results of evaluation levels of Historical sites and city centres.

\subsection{Evaluation the Religious Sites and Traditional Environments}

1. Level of application of the laws of conservation, rehabilitation, development and urban Infill of traditional environments.

2. Level of reuse of heritage buildings to support urban tourism.

3. Level of access to religious sites, traditional environments, and important landmarks.

4. Level of maintenance and occupancy of old buildings for the purposes of supporting urban tourism.

5. Level of lifting abuses from the streets, spaces, cultural areas, and getting rid of harmful occupations that have nothing to do with tourism activities.

6. Level of support for heritage industries and for reviving old and extinct professions.

7. Level of development and maintenance of traditional markets.

8. Level of organization of the physical and visual axes of religious sites and the surrounding spaces.

9. Level of organization of visitor Transits and movement between religious sites and between traditional environments.

Table 4. Shows results of evaluation levels Religious sites and traditional environments.



Table 4 Shows results of evaluation levels Religious sites and traditional environments.

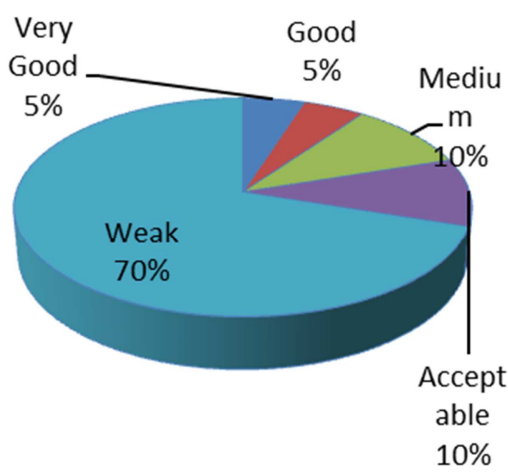

Figure 5. Shows results of evaluation levels Religious sites and traditional environments.

\section{Discuss the Results}

The Evaluation of the General Framework for Urban Tourism in Iraqi cities showed the following results:

1. The results of Evaluation the Organization Levels of City Centers:

The evaluation results indicate that the state of weakness was $40 \%$, the state of admission was $35 \%$, and the average state level was $15 \%$, meaning that the total reached $90 \%$, and this result indicates the state of deterioration of city centers in general and these results do not encourage urban tourism, as they do not meet Local requirements of the local community 
and this requires more effort and time to improve the reality of those cities.

2. The results of Evaluation Levels of the organization of public transportation and external roads:

The results of the evaluation indicate that the condition of weakness was $60 \%$, the state of acceptance was $25 \%$, and the level of the average case was $5 \%$, meaning that the total amounted to $90 \%$ as well, and this result indicates the dissatisfaction of the local community with the state of the external and internal roads and the public transport of the city center and external roads Which are considered the most important pillars of urban tourism, and these results do not encourage urban tourism, as they do not meet the local requirements of the local community, and this requires more the effort, time and money as well to improve the reality of transportation and public roads.

3. The results of Evaluation levels of the Historical sites and city centers:

The evaluation results indicate that the vulnerability was $65 \%$, the acceptance status was $15 \%$, and the average status level was $5 \%$, meaning that the total amounted to $95 \%$ as well. This result indicates that the local community is dissatisfied with the status of historical sites at the level of maintenance and rehabilitation, and ways to reach them And its relationship to urban centers and external roads and these are the most important pillars of urban tourism, and these results do not encourage urban tourism, and this requires more attention, effort, time and money to advance the reality of historical sites and their surroundings.

4. The results of Evaluation levels of the Religious sites and traditional environments

The evaluation results indicate that the vulnerability was $70 \%$, the acceptance was $10 \%$, and the average state was $10 \%$, meaning that the overall total was also $90 \%$. This result indicates that the local community is dissatisfied with the relationship of religious sites to the traditional environments that surround them. In addition to the level of conservation, maintenance, rehabilitation, reuse and incentives, and ways to reach them, this result requires a review of this relationship and attention to religious sites and traditional places as a tourist destination that motivates tourists to move and move between them. It also has certain effects on spatial development.

\section{Conclusion}

Through an analysis of the results of the study of Iraqi cities to assess their ability to be tourist cities that combine local and global characteristics, the research has reached several indicators that do not meet the requirements of urban tourism, therefore it is necessary to work on developing these cities as shown below:

\subsection{City Centres}

Reorganization or formation of city centers to respond to the requirements of urban tourism through:

1. Organizing the urban landscape of cities, by increasing the height of buildings for the main streets, and reviewing the land uses and densities.

2. Activating the economic, social, cultural, environmental, security, and health the efficiency of cities to encourage people to visit them and make them vibrant.

3. The city joins hands, gets rid of interstitial spaces, increases its cohesion and interconnectedness, and makes it with diverse and sequential activities and activities, to encourage people to walk and reduce dependence on car use.

4. Engaging local capital (real estate, money, and ideas) in management and investment and linking it to development.

5. Improving the external appearance of buildings, urban spaces, trees, elements of night lighting and furnishing, cladding their streets and spaces, and defining transit and walking areas and bus stops in accordance with international standards.

6. Get rid of harmful activities and events in it (health, environment, and visual), such as unfulfilled service, commercial, and health activities.

7. Ensuring environmental protection for the transition between the shops and residential sectors for pedestrians and bicycles, by employing some design treatments such as roofed landscaping or afforestation, or directing the streets and residential sectors to address poor geographic guidance.

8. Afforesting the main and subsidiary streets of neighborhoods and residential sectors with trees to provide shade and environmental protection for users during movement, roaming, and moving from one place to another, to improve the internal environment of cities.

9. Furnishing the main streets and spaces with seating and waiting seats on the movement paths in private and public places, including the residential sectors.

10. The use of anthropological values (symbols - myths legends - tales - events - stories - local and historical folklore.....) in the furnishing of spaces to attract people and tourists to them.

11. Supporting the multi-use building in the city centers and the main commercial streets that constitute the urban body of the city, to include residential units and commercial offices on the upper floors and commercial and service stores on the ground floors, because it provides an efficient investment of the land and provides job opportunities and increases the efficiency of the place.

12. Eliminate the visual pollution aspects of Iraqi cities and treat small, detailed damages such as cracking in the tiling and sidewalks, rainwater and sewage checkpoints, parking lots, tree trunks, building entrances, etc.

13. Increase opportunities for housing, accommodation, and hotels for tourists in the city centers.

14. Stopping the transformation of the centers of vital places and streets from commercial centers to healthy places or mixing between them.

15. Isolating health services for transitional and infectious diseases from other services and keeping them away from city centers.

16. Develop the banks of the Tigris River to encourage people and tourists to walk and enjoy the river. 


\subsection{Public Transport and External Roads}

Reconsidering the internal and external transportation system to support urban tourism through:

1. Regulating the external environment surrounding the external roads.

2. Providing highly efficient methods of community service that encourage movement and movement between cities.

3. Maintenance, cleanliness, lighting, and fencing of public roads, in addition to providing recreational and service services, landscaping, and traffic signs through investment.

4. Improving the appearance of roads and organizing spaces for religious events, services, and the external environment.

5. Allocating places designed to revive religious events and organize public services for visitors along the roads towards religious cities, which are temporary and can be dismantled after the end of the events, while providing health and service services and night lighting.

6. Encouraging investors to establish a metro line to transport visitors during and during religious events, operating throughout the year.

7. Using external roads for recreational purposes, hiking and internal trips throughout the year through the establishment of kiosks, cafes, restaurants and service facilities after the completion of religious visitation ceremonies.

\subsection{Historic Sites and City Centers}

Organize the relationship between historical sites, their surroundings and city centers, and get rid of the problems they suffer from in order to support urban tourism through:

1. Enhance its ability to respond to global competition, challenges and traditional tourism requirements.

2. Connecting historical sites to city centers and avoiding making them isolated from their surroundings, which makes them not intended by the general public as a result of the difficulty in reaching them by walking.

3. Developing the areas surrounding historical sites and making them attractive points to motivate people to visit them.

4. Get rid of the abuses and slums that surround the historical sites.

5. Defining the entrances to historical sites and linking them to the public road network.

6. Strengthening the security aspects of the surrounding historical and archeological sites.

7. Maintenance and sustainability of historical sites.

8. Setting indicative and identifying marks for historical and archeological sites.

9. Modifying basic designs to make historical sites vital foci within cities.

10. Involve the owners and developers in managing the areas surrounding the historical sites.
11. Supporting the areas surrounding historical and archeological sites with (hotels - restaurants - exhibitions commercial malls - institutes concerned with the maintenance of heritage buildings - workshops for local traditions and heritage industries and service facilities that support tourism - mixed housing).

\subsection{Religious Places and Traditional Environments in Which They Are Preserved}

Regulating the relationship between religious sites and the surrounding traditional environment through:

1. Avoid crawling traditional environments as cultural places that support religious tourism, which is available to the movement and transformation of tourists.

2. Reconsidering the laws of preservation, rehabilitation, development, maintenance, and urban dictation, especially those that cannot be applied in local heritage places due to the different nature of the local materials used and finding their own local laws.

3. Reuse and occupancy of heritage buildings for the purposes of serving cultural and economic activities in support of tourism.

4. Ensuring easy access to it and making it available to others, whether it is on foot or by car.

5. Avoid leaving old buildings without maintenance or works.

6. Eliminate harmful professions that have nothing to do with tourism activities and lift abuses of streets, spaces, and cultural areas.

7. Supporting heritage industries and reviving old and extinct professions.

8. Preserving and developing traditional markets and heritage sites.

9. Organizing the kinematic and visual aspects of the religious sites and the surrounding spaces.

10. Organizing the movement and movement of visitors between holy cities and between other cities.

As for the recommendations on services and infrastructure, they are general recommendations that must be available in any tourist place. Therefore, it requires reviewing services and infrastructure to support and encourage urban tourism, as follows:

1. Providing the means of communication for tourists and enhancing the sense of security and safety for tourists.

2. Promote health services, water, electricity, sanitation, and waste disposal.

3. Developing public spaces, parks, and gathering places for people.

4. Furnishing the streets with guiding and tariff boards, sitting and waiting seats, and good lighting.

5. Organizing and caring for trees and plants.

6. Promote historical, traditional, religious, and natural sites and important landmarks in city centers and services. 


\section{Appendix}

Table A1. Evaluation of the Framework of Urban Tourism in Iraq.

\begin{tabular}{ll}
\hline Evaluation \\
\cline { 2 - 2 } & Weakness Acceptable Medium Good Very Good \\
\hline
\end{tabular}

First: evaluation of the level of organization of city centers

The level of organization of the urban landscape, the height of the buildings, the uses of the land, and the population and housing densities.

The level of efficiency of cities, economically, socially, urban, environmentally, security, and health.

The level of city solidarity, interstitial spaces, and their cohesion and interdependence.

The level of local capital investment in investment and city management.

The level of organization of streets, movement, ads, signs, and parking stops for buses.

The level of diversity and distribution of activities and events in the city.

The level of harmful occupations in the city (service, health, etc).

The level of environmental treatments for buildings, sidewalks, streets, stores, and city centers.

The Level of attendance of folkloric activities and activities in urban spaces.

The level of supply and circulation of housing units and mixed-use on the main streets of cities.

The level of visual pollution in cities.

The level of diversity of hotels and their geographical distribution to meet the needs of tourists in cities.

The spread of the phenomenon of turning the centers of cities and important streets into health uses.

The level of development of river banks and the surrounding spaces.

Second: evaluation of the level of organization of public transport and external roads

The level of organization of the external environment surrounding the external roads.

The level of efficiency of the roads that encourage tourists to move and move between cities.

Level of maintenance, cleaning, lighting, fencing, furnishing and landscaping of external roads.

The level of organization of spaces for religious events, services and the external environment.

The level of organization of public services for visitors to religious places between cities.

The presence of public transportation for recreational, hiking and inter-city excursions.

The presence of advanced private transportation to discourage tourist between cities.

Third: evaluation of historical sites and city centers

The level of historical sites meeting the requirements of urban tourism and global competition.

The level of linkage of historical sites with city centers.

The level of availability of attractions surrounding the historical sites.

The level of abuses, slums, and expelling activities that surround the historical sites.

The level and clarity of the entrances to historical sites, there accessibility and their connection to the public road network.

The level of security aspects of the surrounding historical and archaeological sites.

The level of rehabilitation and maintenance of historical sites.

The level of indicative and identifying marks of historical and archaeological sites.

The level of support of the areas surrounding the historical and archaeological sites for urban tourism.

Fourth: Evaluating the religious sites and the traditional environments they are in

The level of application of laws for conservation, rehabilitation, development and urban dictation of traditional environments.

The level of reuse of heritage buildings to support urban tourism.

The level of access to religious sites, traditional environments and important landmarks.

The level of maintenance and occupancy of old buildings for the purposes of supporting urban tourism.

The level of elimination of harmful professions from streets, spaces and cultural areas.

The level of support for heritage industries and the revival of old and extinct professions.

The level of development and maintenance of traditional markets.

The level of organization of the physical and kinematic axes of the religious sites and the 
Evaluation

Weakness Acceptable Medium Good Very Good

surrounding spaces.

The level of organization of visitor movement and movement between religious sites and

traditional environments.

\section{References}

[1] United Nations, 1999, "Handbook of Input-Output Table Compilation and Analysis", Studies in Methods: Handbook of National Accounts, Series F, No. 74, UN, New York, p. 211. https://digitallibrary.un.org/record/370160.

[2] Essays, UK. (November 2018). Importance of Urban Tourism. Retrieved from,

https://www.ukessays.com/essays/tourism/importance-of-urba n-tourism-tourism-essay.php?vref $=1$.

[3] From Wikipedia, the free Encyclopedia.

[4] Word tourism Organization (UNWTO)," global Report on City Tourism", Am Reports: Volume, 2012.

[5] Cave, J and L. Jolliffe (2012) Urban Tourism. Tourism: The Key Concepts. Robinson, P. (Ed.) London: Routledge. pp 268-270.

[6] AKSOZ, Ozan Emre, BÂC, Dorin Paul;" The Importance of Urban Tourism for Hotel Marketing Polices: The Case of ESKIŞEHIR"; Geo Journal of Tourism and Geosites Year V no. 1, vol. 9, May 2012.

[7] Ülke Evrim Uysal;" Urban Tourism in Istanbul: Urban Regeneration, Mega-events and City Marketing and Branding"; Publications of the Department of Social Research 2015: 6 Social and Public Policy.

[8] Adillón, Ramón;" Diamond Model: A theoretical framework for the sustainable development of tourism", Arts and Humanities Open Access Journal, Volume 3 Issue 1 - 2019.

[9] N. Giriwati, R. Homma \& K. Iki," Urban tourism: designing a tourism space in a city context for social sustainability"; The Sustainable City VIII, Vol. 1, 2013.

[10] V Ariani;"Integrated city as a model for a new wave urban tourism" IOP Conference Series: Earth and Environmental Science, Volume 126, Friendly City 4 'From Research to Implementation For Better Sustainability' 11-12 October 2017, Medan, Indonesia.

[11] Daniel Barrera-Fernandez, Marco Hernández-Escampa,
Antonia Balbuena Vázquez;" Tourism Management in the Historic city. The impact of Urban planning polices "; International Journal of Scientific Management and Tourism, 2016, Vol. 2 No4 pp 349-367.

[12] "Urban tourism"; https://ceopedia.org/index.php/Urban_tourism.

[13] McClain, Joe; "City Tourism Brings Great Profits to the Communities", Tourism Review Online Magazine, Jun 30, 2015.

[14] (THE TOURISM INDUSTRY: MODULE 7); https://nmssanctuaries.blob.core.windows.net/sanctuaries-prod /media/archive/management/pdfs/Day7_INDUSTRY_MANU AL.pdf.

[15] Tao wei, ZHONG wen-hui, HONG yan; " Urban Tourism Research Methodology-A case study of Guangdong-Hong Kong-Macao area", Chinese Geographical Science, Volume 15, Number 2, pp-177-178, 2005.

[16] Galdini, Rossana;" Tourism and the city: opportunity for regeneration"; Tourismos: An International multidisciplinary Journal of Tourism Volume 2, Number 2, Autumn 2007, University of Calabria.

[17] Ardahaey, Fateme Tohidy, "Economic Impacts of Tourism Industry", International Journal of Business and Management Vol. 6, No. 8; August 2011.

[18] Deborah Edwards, Tony Griffin, Bruce Hayllar and Brent Ritchie," Understanding Urban Tourism Impacts: An Australian study"; Sustainable Tourism cooperative research centre.

[19] European Commission (1998). Sustainable urban development in the European Union: a framework for action, Communication from the Commission, October 28.

[20] Kreag, Glenn; "The Impacts of Tourism "Publication Number: T 13 Date: April, 2001, University of Minnesota, http://www.seagrant.umn.edu/tourism/pdfs/ImpactsTourism.p df.

[21] Lickorish, Leonard J., Jenkins, Carson L.; "An Introduction to Tourism", British Library Cataloguing in Publication Data, ISBN 075061956 2, 1997. 